\title{
Changes in thrombospondin-1 levels in the endothelial cells of the anterior pituitary during estrogen-induced prolactin-secreting pituitary tumors
}

\author{
Abby J Sarkar, Kirti Chaturvedi, Cui Ping Chen and Dipak K Sarkar \\ Endocrinology Program and Department of Animal Sciences, Rutgers, The State University of New Jersey, 84 Lipman Drive, New Brunswick, \\ New Jersey 08901, USA \\ (Requests for offprints should be addressed to D K Sarkar; Email: sarkar@aesop.rutgers.edu)
}

\begin{abstract}
Thrombospondin-1 (TSP-1), a multifunctional matrix glycoprotein, has been shown to control tumor growth by inhibiting angiogenesis in various tissues. However, the role of this glycoprotein in pituitary angiogenesis is not well studied. In this report, we determined the changes in the production and action of TSP-1 on endothelial cells in anterior pituitary following estradiol treatment, which is known to increase prolactinsecreting tumor growth and vascularization in this tissue. We showed that TSP-1 immunoreactive protein is distributed in the anterior pituitary, particularly in the endothelial cells. Estradiol treatment for 2 and 4 weeks decreased the total tissue

immunoreactive level of TSP-1 as well as the endothelial cell-specific immunoreactive level of this protein in the anterior pituitary. The steroid treatment also decreased the protein levels of TSP-1 in anterior pituitary tissues and in purified pituitary endothelial cells in primary cultures. Determination of the effects of TSP-1 on proliferation and migration of pituitaryderived endothelial cells in primary cultures elucidated an inhibitory action of TSP-1 on these vascular cell functions. These results suggest that locally produced TSP-1 may regulate estrogen angiogenic action on the pituitary.

Journal of Endocrinology (2007) 192, 395-403
\end{abstract}

\section{Introduction}

Angiogenesis is a process by which new blood vessels are formed from the pre-existing vessels. This is an important event in physiologic and pathologic condition (Folkman 1995, Hanahan \& Folkman 1996). Endothelial cells carry all the information regarding the formation of capillary network. Various angiogenic and anti-angiogenic molecules control the process of neovascularization by increasing the activity of endothelial cells. During disease conditions like cancer or tumor formation, an increase in capillary network takes place due to positive or negative balance between angiogenic and non-angiogenic factors (Kalluri 2003). Prolactinomas, prolactin (PRL)-secreting lactotropic tumors and most frequently occurring neoplasms in the human pituitary (Hardy et al. 1980), are vascularized tumors in some animal models (Gorczyca \& Hardy 1988, Schecter et al. 1988). In the human pituitary, a relationship between increased vascularity and several aspects of prolactinoma behavior has also been demonstrated (reviewed in De la Torre et al. 2005). These data suggest that angiogenesis could be an important process during pituitary tumor growth in the pituitary.

The ovarian steroid estradiol is known to increase the proliferation of PRL-secreting lactotrophs in humans as well as in laboratory animals (Sarkar et al. 1982, Gooren et al.
1988). Studies of estradiol-induced prolactinomas in estrogen-susceptible rats also identified significant angiogenesis of the pituitary tumors (Elias \& Weiner 1987). It has been shown previously that estrogen exposure can increase the levels of angiogenic factors, like basic fibroblast growth factor and vascular endothelial growth factor (VEGF; Banerjee et al. 1997, Hentges \& Sarkar 2001), while there are no reports on the effect of estrogen on anti-angiogenic factors like thrombospondin-1 (TSP-1) in the pituitary. TSP-1 is a multifunctional protein that belongs to a family of extracellular matrix binding proteins and is implicated in the regulation of tumor growth via the inhibition of angiogenesis (Adams \& Lawler 2004, Sid et al. 2004). TSP-1 is primarily secreted by platelets (Lawler \& Hynes 1986). Although a variety of other cells are also known to produce TSP-1, most of them are strongly bound to extracellular matrix rather than free in the circulation (Lawler 2002). The potential role of TSP-1 as an inhibitor of tumor angiogenesis in the pituitary has not been studied. In this study, we determined the changes in the pituitary levels of TSP-1 during tumor development in estrogen-treated ovariectomized rats. We also determined the effects of estradiol on the levels of TSP-1 in endothelial cells both in vivo and in vitro and evaluated the effect of TSP-1 on endothelial cell proliferation and migration in vitro. 


\section{Materials and Methods}

\section{Animals and surgery}

Female F344 rats with a body weight of 160-200 g, obtained from Simonsen Laboratories (Gilroy, CA, USA), were housed in a controlled environment (temperature, $22{ }^{\circ} \mathrm{C}$; lights on, 0500-1900 h) and provided with rodent chow meal and water available ad libitum. Animals were ovariectomized bilaterally and subcutaneously (s.c.) implanted with a $1 \mathrm{~cm}$ estradiol-17 $\beta$ (Sigma)-filled silastic capsule (Dow Corning Corp., Midland, MI, USA) or an empty silastic capsule using sodium pentobarbital anesthesia (40-50 mg/kg, i.p.). Animals were kept for a period of 2 and 4 weeks after surgery and then used as donors for pituitaries. Animal surgery and care were performed in accordance with institutional guidelines and complied with National Institute of Health's (NIH) policy. The animal protocol was approved by the Rutgers Animal Care and Facilities Committee.

For immunohistochemistry, pituitaries were obtained and immediately fixed with $4 \%$ formalin, and the sections were processed for immunostaining. For determining the levels of TSP-1, PRL and CD31, pituitaries were homogenized in buffer $(\mathrm{pH} \mathrm{7.5)}$ containing $150 \mathrm{mM}$ Tris- $\mathrm{HCl}, 300 \mathrm{mM}$ $\mathrm{NaCl}, 1 \mathrm{mM} \mathrm{MgCl}, 1 \%$ Triton-X, 10\% glycerol and a protease inhibitor cocktail (Sigma) on ice using glass-glass homogenizer. Homogenate was centrifuged at 13000 r.p.m. for $10 \mathrm{~min}$, supernatant was collected and protein levels were determined using Bio-Rad protein assay. Approximately, $50 \mu \mathrm{g}$ protein from each sample were mixed with gel loading dye and loaded on gel to detect levels of TSP-1, PRL, and CD31 using western blotting as described below.

\section{Immunohistochemistry}

Formalin fixed pituitaries were embedded in paraffin and cut into sections. Sections were rehydrated, microwave-heated in citrate buffer ( $\mathrm{pH} \mathrm{6)}$ for $10 \mathrm{~min}$, and then washed under tap water for $10 \mathrm{~min}$. Sections were washed with $0 \cdot 1 \mathrm{M}$ PBS for $5 \mathrm{~min}$, and then blocked with PBS containing 2.5\% horse serum. Sections were incubated with a $1 / 25$ dilution of primary mouse anti-TSP-1 antibody (Abcam, Inc, Cambridge, MA, USA) in the $1.5 \%$ blocking buffer overnight at $4{ }^{\circ} \mathrm{C}$. For staining with diaminobenzidine tetrahydrochloride (DAB), sections were processed by a streptavidin/peroxidase complex method using the Vectastain Universal Quick Kit (Vector Labs, Burlingame, CA, USA). For double staining with immunofluorescent dyes, sections were incubated simultaneously with the primary mouse anti-TSP-1 antibody $(1 / 25)$, and goat antiCD34 (1/20; Santa Cruz Biotechnology, Santa Cruz, CA, USA) in blocking buffer for $48 \mathrm{~h}$ at $4{ }^{\circ} \mathrm{C}$. We used antibody for CD34 for in situ detection of endothelial cells in the pituitary sections, because this antibody gave better reaction to the immunofluorescence staining than the CD31 antibody that we used for isolation of endothelial cells and for protein measurement by the western blot technique. Both CD31 and CD34 are reliable endothelial cell markers (Parums et al. 1990, Vidal et al. 2001). After rinsing in Tris-buffer, the sections were incubated in Alex Fluor 488 donkey anti-mouse $\operatorname{IgG}(\mathrm{H}+\mathrm{L})$ and Alexa Fluor 594 donkey anti-goat $\operatorname{IgG}(\mathrm{H}+\mathrm{L})$ (1:400; Molecular Probe, Eugene, Oregon, USA) for $40 \mathrm{~min}$. Both of these secondary antibodies failed to stain the tissue sections in the absence of a primary antibody. Fluorescent images were captured with a Cool SNAPpro charge couple device (CCD) camera coupled to a NikonTE 2000 inverted microscope. Images were processed with Adobe Photoshop 7·0. The immunoreactive level of protein in the pituitary was determined by visual inspection of six sections of each pituitary by two independent investigators as a blind study. The staining intensity was rated from the highest $(+++)$ to the lowest (0).

\section{Endothelial cell culture}

We used anti-CD31 antibody and magnetic separation procedures to isolate endothelial cells from the pituitary. CD31 is strongly expressed by all endothelial cells and weekly by several types of leukocytes (Parums et al. 1990). In normal pituitary, anti-CD31 antibody labels $5-7 \%$ population of endothelial cells. Pituitaries from ovariectomized and 4 weeks estradiol-treated rats were collected and processed for endothelial cell isolation as described by us recently (Chaturvedi \& Sarkar 2006). Briefly, pituitaries were minced by passing through an 18 gauge needle and digested in Hank's balanced salt solution (HBSS) supplemented with collagenase, DNAse and BSA for $40 \mathrm{~min}$ at $37^{\circ} \mathrm{C}$ as described earlier (Sarkar et al. 1998). The digested tissue was filtered through a $30 \mu \mathrm{m}$ nylon mesh. The pituitary cells were resuspended in $500 \mu \mathrm{l}$ binding buffer (PBS, 0.5\% BSA, $2 \mathrm{mM}$ EDTA, 0.05\% sodium azide) containing mouse anti-rat CD31-PE-conjugated antibody $(1 \mu \mathrm{g} /$ million cells; Research Diagnostics Inc. Flanders, NJ, USA) for 30 min at $4{ }^{\circ} \mathrm{C}$. Cells were washed with washing buffer ( $1 \mathrm{mM}$ PBS, $2 \mathrm{mM}$ EDTA, $0 \cdot 05 \%$ sodium azide) and then incubated with anti-PE antibody labeled with magnetic beads (anti-PE beads; $20 \mu \mathrm{l} / 10$ million cells; Miltenyi Biotec, Aubum, CA, USA) for $15 \mathrm{~min}$ at $4{ }^{\circ} \mathrm{C}$ in binding buffer. Cells were washed and then resuspended in $500 \mu \mathrm{l}$ binding buffer. These magnetic labeled cells were subjected to magnetic separation (positive selection) using an autoMACS magnetic sorter (Miltenyi Biotec). Positive cells were collected, washed, and resuspended in basal endothelial growth media-2 (EGM-2) containing growth factors (Cambrex Bioscience; Walkersville, MD, USA). Cells were plated in $25 \mathrm{~cm}^{2}$ flask and media were changed after $24 \mathrm{~h}$ and then after every 2-3 days. The percentage of positive cells was determined by flow cytometry. This separation gave us approximately 95\% CD31 positive cells. For determining the effect of estradiol on TSP-1 levels in endothelial cells, purified endothelial cells from pituitary were first grown in phenol red-free EGM-2 media containing growth factors for $48 \mathrm{~h}$ followed by incubation in serum supplement containing EGM-2 basal media for $24 \mathrm{~h}$. Cells were then treated with $10 \mathrm{nM}$ estradiol for various time periods. Cells were 
extracted using lysis buffer and levels of TSP-1 and actin were detected by the western blot measurement.

\section{Cell proliferation assay}

For cell proliferation experiments, 10000 endothelial cells/well in 96-well plates were grown in growth factor containing EGM-2 media for $48 \mathrm{~h}$. After that cells were washed twice with serum-free media and TSP-1 $(5 \mu \mathrm{g} / \mathrm{ml}$; Sigma), VEGF (50 ng/ml; Sigma), or TSP-1 and VEGF were added to cell cultures in $2.5 \%$ fetal bovine serum containing EGM-2 basal media for $24 \mathrm{~h}$. The cultures were treated with $0 \cdot 5 \mu \mathrm{Ci} \quad\left[\right.$ methyl- $\left.{ }^{3} \mathrm{H}\right]$-thymidine (specific activity $82.2 \mathrm{Ci} / \mathrm{mM}$; Amersham Corporation) per well for $8 \mathrm{~h}$ prior to harvesting. Cells were harvested using a cell harvester (Packard Bioscience, Meriden, CT, USA) and counted in a liquid scintillation counter.

\section{Cell migration assay}

Cell migration was performed using a cell migration assay kit (Chemicon International, Temecula, CA, USA) as per manufacturer's instructions. Briefly, endothelial cells were grown in $75 \mathrm{~cm}^{2}$ flasks. Cells were treated with serum-free media for $24 \mathrm{~h}$ before plating them on assay plate. Cells were trypsinized next day and resuspended in EGM-2 basal media. Each well of 96-well plate migration chamber was plated with $1.5 \times 10^{4}$ cells. This migration chamber was inserted in 96-well feeder tray, which contained TSP-1 $(5 \mu \mathrm{g} / \mathrm{ml})$, VEGF $(50 \mathrm{ng} / \mathrm{ml})$, or TSP-1 and VEGF. Treatment was done in quadruplicate. Migratory cells on the bottom of insert membrane were detached using cell detachment buffer provided with the kit. Migrated cells were subsequently lysed and detected by CyQuant GR dye. This green fluorescent dye exhibits strong fluorescence enhancement when bound to cellular nucleic acids. The data are presented in fluorescent units.

\section{Western blot}

Equal amount of protein from each sample was resolved on 7.5\% SDS/PAGE and transferred overnight to immobilon-P PVDF membranes (Millipore, Bedford, MA, USA). Membranes were incubated with mouse anti-TSP-1 (1:1000; BD Bioscience, San Diego, CA, USA), mouse CD31 antibody (1:500; Chemicon International), PRL (anti-rat PRL-S-9; 1:200 000; National Institute of Diabetes and Digestive and Kidney Diseases; NIDDK), or anti-actin (Oncogene Research Product, San Diego, CA, USA) antibody for $1 \mathrm{~h}$ at room temperature in blotting buffer ( $\mathrm{pH} 7 \cdot 5)$ containing $5 \%$ milk, $50 \mathrm{mM}$ Tris- $\mathrm{HCl}$, $150 \mathrm{mM} \mathrm{NaCl}$, and $0 \cdot 1 \%$ Tween-20. Membranes were then washed and incubated with peroxidase-conjugated anti-mouse antibody for $1 \mathrm{~h}$. Later, membranes were washed and then developed using ECL western blot chemiluminescence reagent (Amersham Biosciences). For quantification of protein levels, band intensities of the protein were determined using Scion Image software and normalized to the corresponding actin band intensities. Actin served as an internal control to control the loading and the transfer of equal amounts of protein samples.

\section{Statistical analysis}

The data shown in the figures and the text are means \pm s.E.M. Comparisons between two groups were made using $t$-tests. Data comparisons among multiple groups were done using one-way ANOVA. Post hoc tests involved the Student-Newmann-Keuls test. A value of $P<0.05$ was considered significant.

\section{Results}

\section{Immunocytochemical localization of TSP-1 in the anterior pituitary: effect of estradiol}

Determination of the immunoreactivity of TSP-1 in the pituitary of adult ovariectomized female rats showed that cells containing this protein immunoreactivity were distributed throughout the anterior part of the pituitary gland. Many of the TSP-1 immunoreactive cells in the anterior pituitary were in the areas surrounding the capillary linings. The intensity of TSP-1 immunoreactive staining in the anterior pituitary was decreased particularly in the cells of pericapillary lining after 2 and 4 weeks of estradiol treatment in ovariectomized rats as compared with control-treated ovariectomized rats (Fig. 1 and Table 1). Characterization of the TSP-1 immunoreactive cells in the anterior pituitary revealed that many of these cells were colocalized with CD34-positive endothelial cells surrounding the vessels (Fig. 2), suggesting the possibility of involvement of TSP-1 protein in the regulation of endothelial cell functions. Estradiol treatment moderately decreased TSP-1 immunoreactivity in CD34-positive cells surrounding the vessels at 2 weeks and markedly reduced TSP-1 immunoreactivity at 4 weeks after estradiol treatment in ovariectomized rats (Fig. 2 and Table 1).

\section{Effect of estradiol on PRL, TSP-1, and CD31 protein levels} in the anterior pituitary

Estradiol treatment induces prolactinomas and increases endothelial cells proliferation in Fischer 344 rats (reviewed by Turner et al. 2003, Sarkar 2006). Hence, we determined the levels of PRL, TSP-1, and endothelial cell surface protein CD31 following 2 and 4 weeks after estradiol treatment (Fig. 3). Western blot analysis revealed that the level of PRL in the pituitary cells was increased at 2 and 4 weeks of estradiol treatment. However, TSP-1 levels in the anterior pituitary cells were moderately (not significantly) reduced at 2 weeks and significantly decreased at 4 weeks after the steroid treatment. The level of CD31 in the pituitary cells did not change significantly after the treatment of estradiol in ovariectomized rats, suggesting that the steroid does not effect the production of this cell surface protein (Fig. 3). 

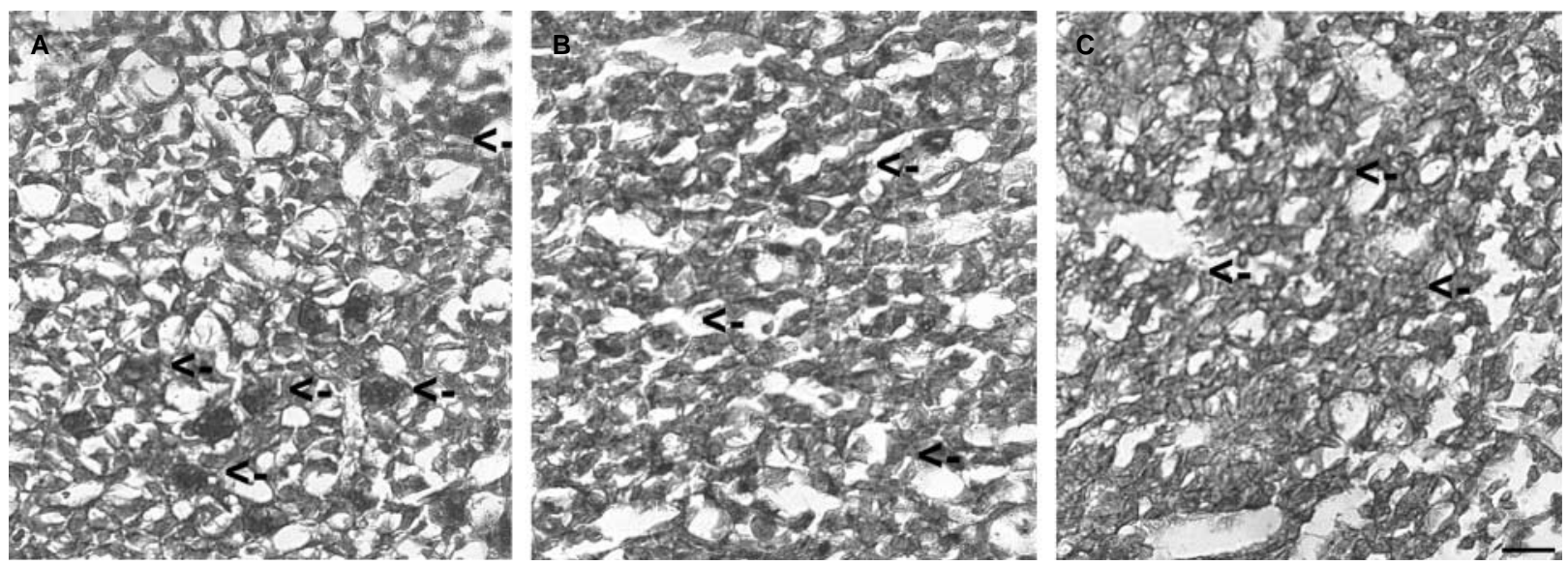

Figure 1 Estradiol-induced changes in the TSP-1 immunoreactivity in the pituitary. Pituitaries were obtained from ovariectomized rat with an empty implant for 2 weeks (A) or with an estradiol implant for 2 (B) or 4 weeks (C) and stained for TSP-1 immunoreactivity using TSP-1 antiserum and standard immunostaining procedures. With DAB as chromagen, TSP-1 immunostaining is manifested as a brown reaction product. Sections were counterstained with hematoxylin, which accounts for the blue nuclear staining in each cell. Some of the cells exhibiting TSP-1 immunoreactivity around some of the vascular spaces are identified by arrows. Scale bar is $20 \mu \mathrm{M}$.

Effect of estradiol on the level of TSP-1 in endothelial cells: in vitro studies

In order to detect whether the estradiol-induced change of TSP-1 level in the anterior pituitary is reflected on endothelial cells as well, we determined the effect of the steroid on endothelial cells in primary cultures. Endothelial cells were purified and grown in culture and treated with various doses of estradiol $(0-10 \mathrm{nM})$ in the presence and absence of an effective dose (100 nM) of and anti-estrogen (ICI 182 780; Chaturvedi $\&$ Sarkar 2004). The steroid concentration dose-dependently decreased the levels of TSP-1 in the endothelial cells in primary cultures (Fig. 4B). The maximal effective dose of estradiol was $10 \mathrm{nM}$. The TSP-1-suppression effect of estradiol was completely blocked by the anti-estrogen. The estradiol's TSP1 -suppression effect was also time-dependent (Fig. 4A). The maximal TSP-1 response to estradiol was observed at $18 \mathrm{~h}$, when tested between a period of 1 and $18 \mathrm{~h}$.

\section{Effect of TSP-1 on basal and VEGF induced proliferation and migration of endothelial cells}

In order to determine whether the TSP-1 has a regulatory role in pituitary angiogenesis process, we evaluated the effects of TSP-1 on basal and VEGF (angiogenesis-stimulating factor; Lawler 2002)-induced proliferation and migration of endothelial cells in primary cultures. The doses of VEGF and TSP-1 used were previously determined to be effective in regulating proliferation and migration of endothelial cells (Sengupta et al. 2004, Chaturvedi \& Sarkar 2006). As shown in Fig. 5A and B, VEGF increased proliferation and migration of the pituitary endothelial cells, while TSP-1 suppressed the VEGF-induced proliferation and migration of these cells in primary cultures.

\section{Discussion}

In the present study, we show for the first time the production and action of TSP- 1 in the anterior pituitary changes during the estrogen-induced prolactinomas. The glycoprotein TSP1 immunoreactivity was highly expressed around the pericapillary lining of the pituitary tissue. Colocalization studies revealed that TSP-1 immunoreactivity was expressed in CD34-positive endothelial cells surrounding the vessels. Estrogen treatment decreased TSP-1 immunoreactivity in the anterior pituitary particularly in the endothelial cells surrounding the vessels of this gland. The steroid also decreased the cellular level of TSP-1 without changing the cellular levels of endothelial cell surface marker protein CD31 in the anterior pituitary. Estradiol concentration-dose

Table 1 Estradiol (E2)-induced changes in the TSP-1 immunoreactive intensity, in the anterior pituitary (AP), and in CD31-positive vessels in the AP of ovariectomized (Ovx) rats. $n=3$

Immunoreactive intensity in the AP (arbitrary unit)

\section{Treatment}

Ovx (2 and 4 weeks)

$\mathrm{Ovx}+\mathrm{E} 2$ (2 weeks)

$\mathrm{Ovx}+\mathrm{E} 2$ (4 weeks)

$$
\begin{aligned}
& +++ \\
& ++ \\
& ++
\end{aligned}
$$

Immunoreactive intensity in the CD31-positive vessels (arbitrary unit)

$$
\begin{aligned}
& ++++ \\
& ++/+ \\
& +/ 0
\end{aligned}
$$



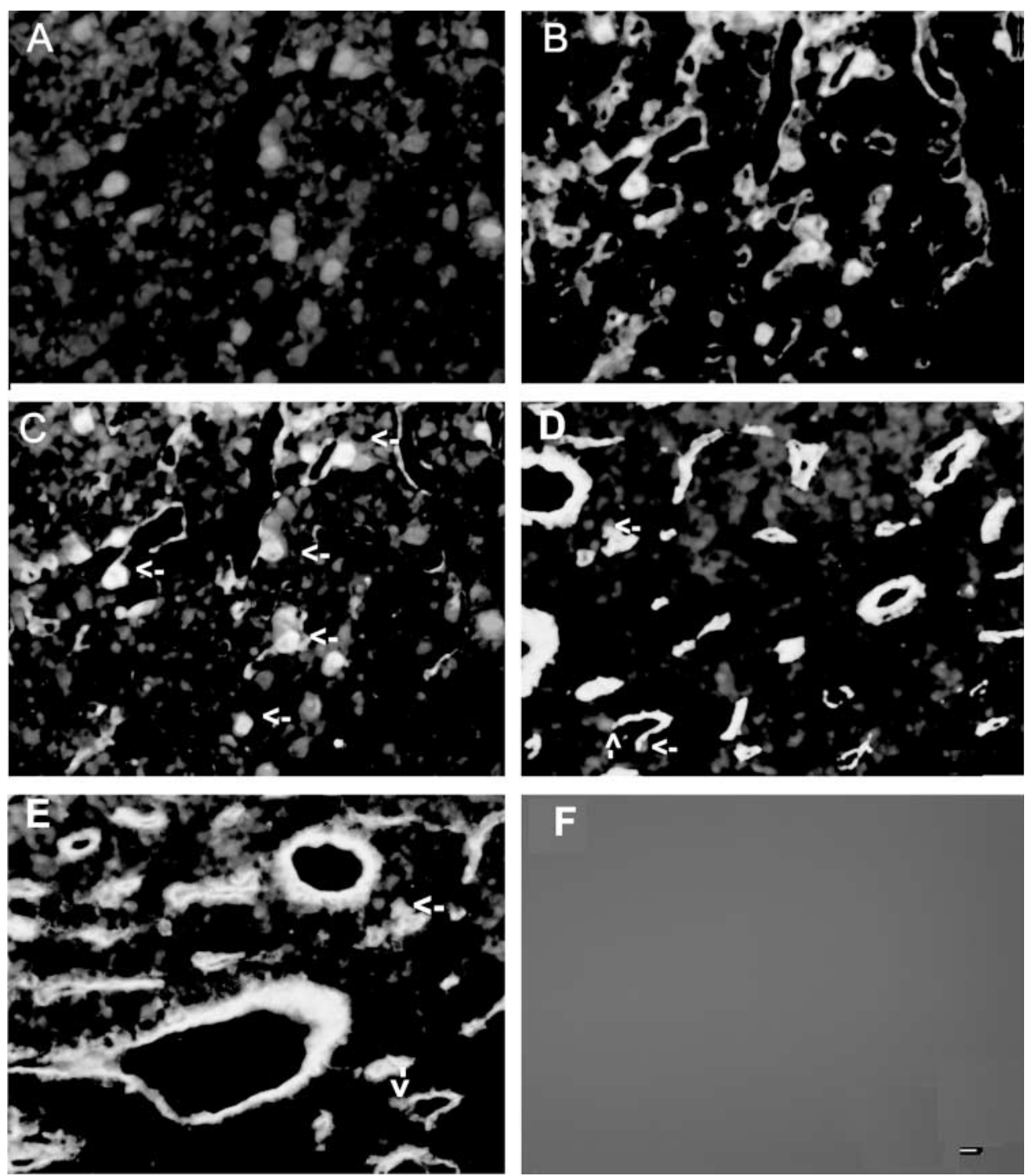

Figure 2 Colocalization of TSP-1 immunoreactivity with CD34 immunoreactivity in the anterior pituitary: effect of estradiol. (A-C) Representative photographs showing colocalization of TSP-1 and CD34 immunoreactivity in the pituitary of an ovariectomized rat with an empty implant for 4 weeks. TSP-1 immunofluorescence staining is shown in red (A) and CD34 is in green (B) and doubled labeled cells are shown in yellow (C). (D and E) Representative photograph showing immunofluorescence staining of TSP-1 and CD34 in anterior pituitaries of ovariectomized rat with an estradiol implant for 2 (D) or 4 weeks (E). Some of the double-labeled cells are shown by arrows.

Immunofluorescence staining was absent when the section was stained in the absence of primary antibodies (F). Scale bar is $20 \mu \mathrm{M}$.

dependently decreased the TSP-1 levels in pituitary-derived endothelial cells in primary cultures. An anti-estrogen prevented the TSP-1-inhibitory effect of estradiol. TSP-1 inhibited the VEGF-induced increase in pituitary-derived endothelial cell proliferation and migration in primary cultures. These data support a role of locally produced TSP-1 in estradiol-regulated neovascularization in the pituitary.

In the pituitary, Jugenburg et al. (1995) has shown an association between the microvessel density as a measure of angiogenesis and tumor behavior; higher microvessel densities were found in pituitary carcinomas than in pituitary adenomas. Higher degree of vascular densities was also found in macroprolactinomas than in microprolactinomas (Errio et al. 1986, Turner et al. 2003). Studies of estradiol-induced prolactinomas in estrogen-susceptible rats showed direct correlation with the vascularization and the tumor growth (Monnet et al. 1984, Elias \& Weiner 1987). In the human pituitary, a relationship between increased vascularity and several aspects of prolactinoma behaviors such as size, invasiveness, cystic component and hemorrhage, surgical outcome, and malignancy have been demonstrated (reviewed 
A

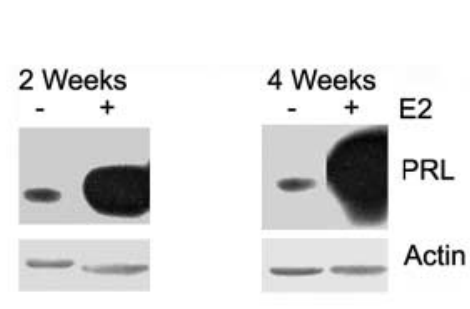

C
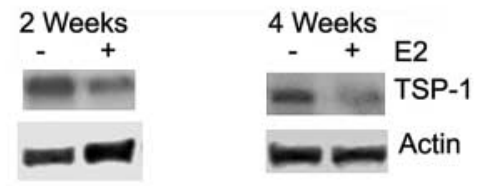

B
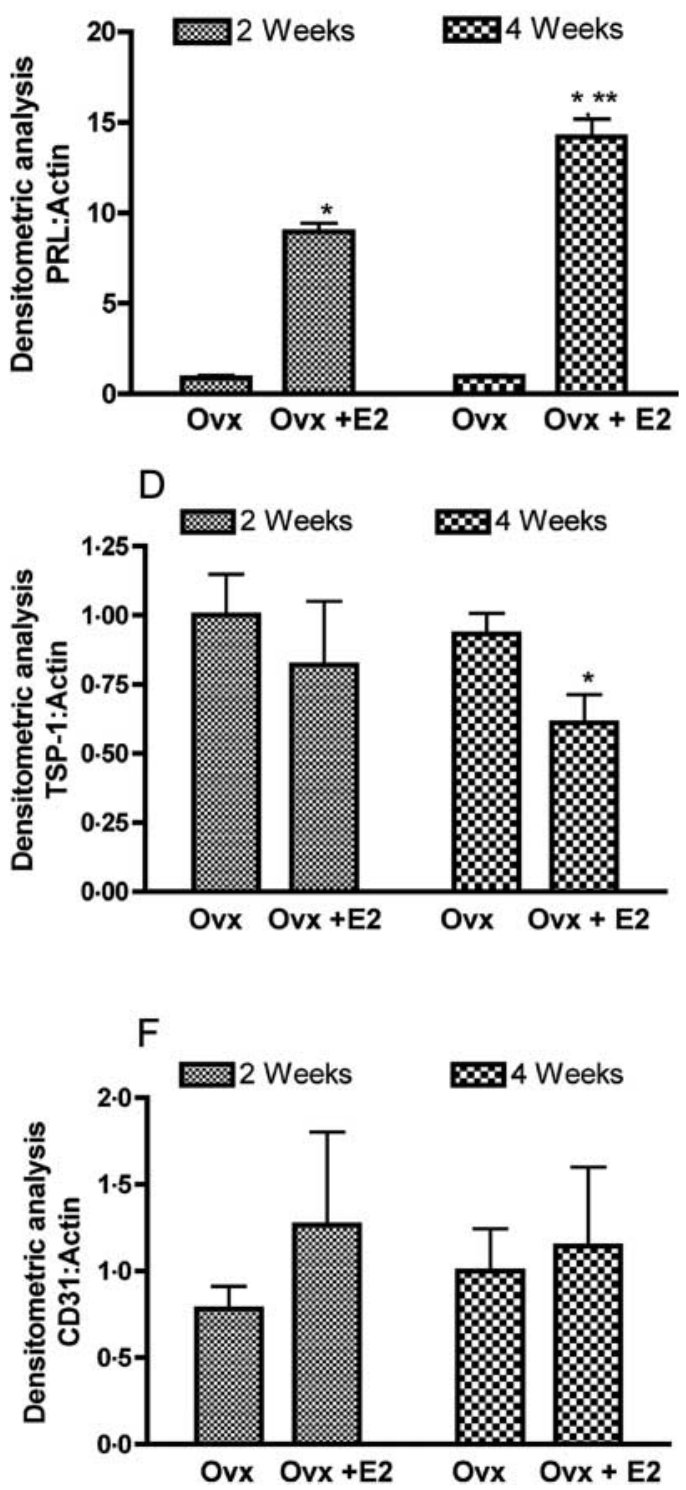

Figure 3 Estradiol-induced changes in the levels of PRL, TSP-1, and CD31 proteins in the pituitary tissues Pituitaries of F344 rats that were ovariectomized and treated with an empty implant (Ovx) or estradiol implant (Ovx +E2) for 2 and 4 weeks were used for measurement of PRL (A and B), TSP-1 (C and D), and CD31 (E and F) levels by western blot. Left panels show representative blots. Right panels show the mean \pm S.E.M. ratios of band intensities of proteins (PRL, TSP-1, and CD31) and actin. Each bar represents mean \pm s.E.M. of four different animals. ${ }^{*} P<0.05$ compared with the Ovx group; ${ }^{* *} P<0.05$ compared with the Ovx $+\mathrm{E} 2$ treated at 2 weeks groups.

in Turner et al. 2003, De la Torre et al. 2005). Morphological studies in human pituitary adenoma also showed increased vascularization to adenomas (Gorczyca \& Hardy 1988, Schecter et al. 1988). These data suggest that angiogenesis is critical to pituitary PRL-secreting tumor growth and progression.

Angiogenesis involves interaction with various extracellular matrix components, endothelial cell proliferation, migration, and differentiation into capillaries (Folkman 1995, Hanahan \& Folkman 1996). Various pro-angiogenic and anti-angiogenic molecules control the process of neovascularization by increasing the activity of endothelial cells (Nguyen et al. 1994, Relf et al. 1997). Endothelial cells are the cells which carry information regarding capillary network (Folkman 1996). During tumor formation, an increase in capillary network takes place due to positive or 
A

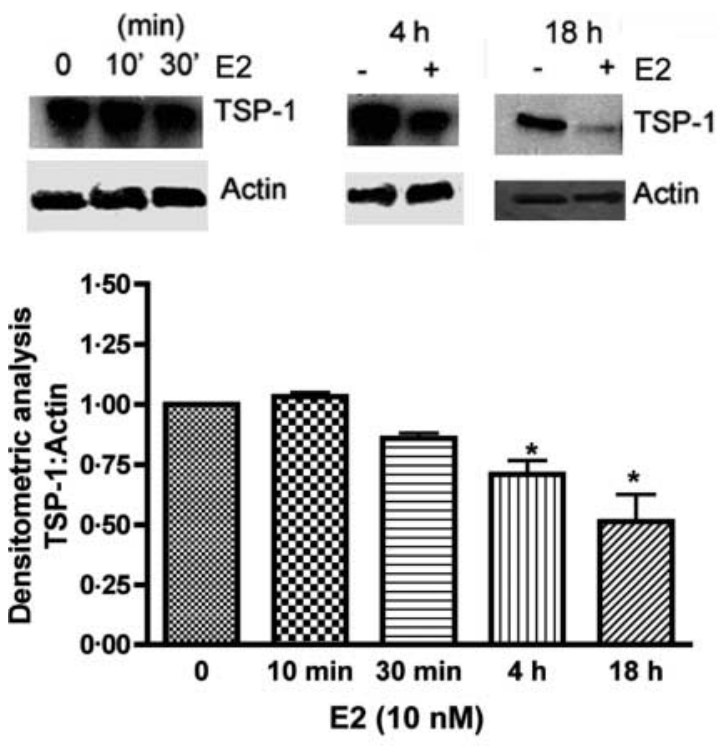

B
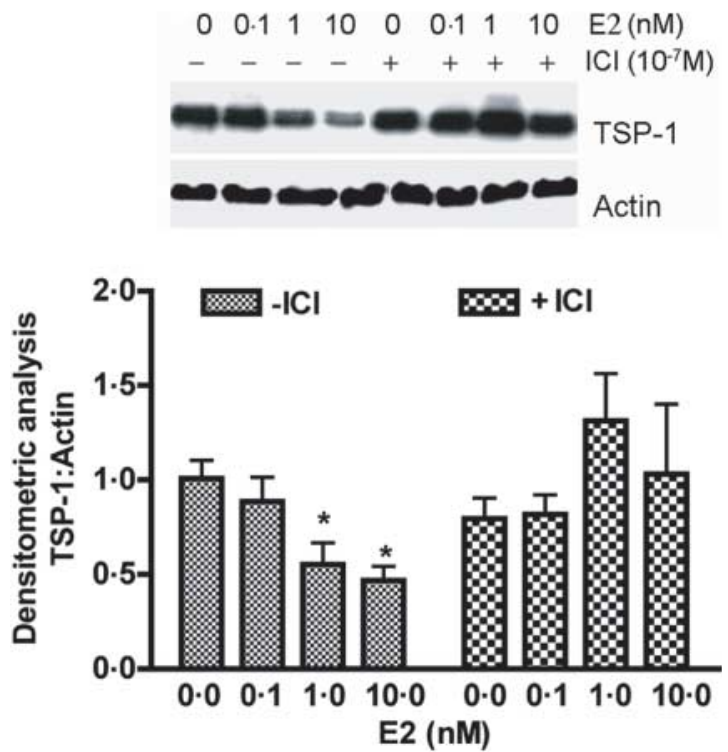

Figure 4 Estradiol-induced changes in TSP-1 protein levels in pituitary endothelial cells in primary cultures. (A) Time-dependent effect of estradiol. Endothelial cells treated with estradiol (E2;

$10 \mathrm{nM}$ ) for various time periods were lysed and used for detection of TSP-1 and actin levels using western blot. Upper panel in each figure shows representative bands for TSP- 1 and lower panels shows the representative bands for actin. The mean \pm S.E.M. ratios of band intensities of TSP-1 and actin are shown in the histograms. Each bar represents mean \pm S.E.M. of four separate experiments. ${ }^{*} P<0 \cdot 05$ compared with the control group. (B) Concentration-dependent effect of estradiol in the absence and presence of anti-estrogen $\mathrm{ICI}$ 182780 . Primary cultures of endothelial cells were pretreated with ICI $182780\left(10^{-7} \mathrm{M}\right)$ for an hour followed by estradiol $(0 \cdot 1-10 \mathrm{nM})$ for $18 \mathrm{~h}$. Levels of TSP-1 and actin were measured using western blot. Representative blots are shown in the upper panel. Data are shown on the lower panel. Each bar represents mean \pm S.E.M. of 4-5 separate experiments.
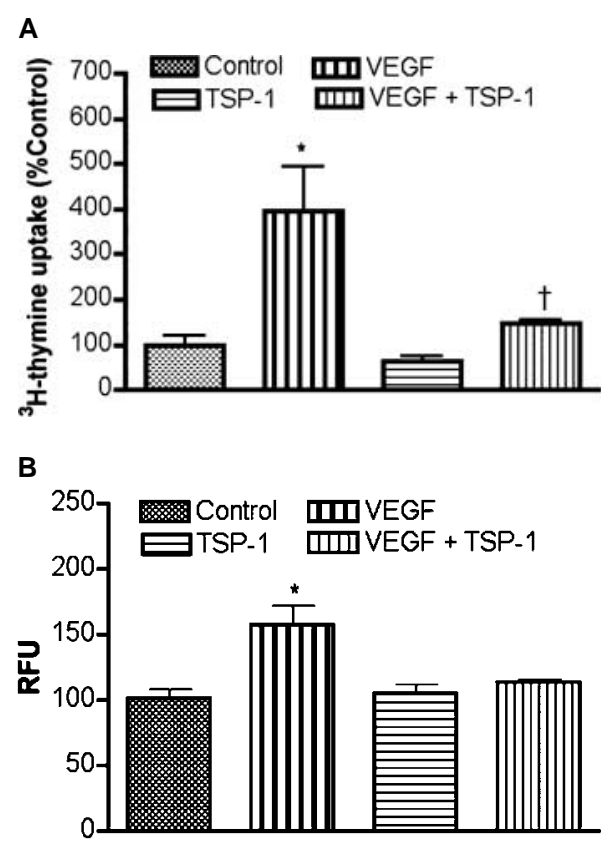

Figure 5 Effect of TSP-1 on basal and VEGF-induced proliferation and migration of endothelial cells. (A) Cell proliferation assay. Endothelial cells grown in 96-well plate were treated with TSP-1 $(5 \mu \mathrm{g} / \mathrm{ml})$, VEGF $(50 \mathrm{ng} / \mathrm{ml})$, or VEGF and TSP-1 for $24 \mathrm{~h}$. The cultures were treated with $0.5 \mu \mathrm{Ci}\left[\right.$ methyl- $\left.{ }^{3} \mathrm{H}\right]$-thymidine per well for $8 \mathrm{~h}$ prior to harvesting. Data are presented as percentage of control. Each bar diagram represents mean \pm s.E.M.; $n=5-6$. ${ }^{*} P<0 \cdot 01$ compared with control group. ${ }^{\dagger} P<0 \cdot 05$ compared with VEGF-treated groups without TSP-1. (B) Cell migration assay. Equal numbers of serum-starved cells were plated on the migration tray with filter $(8 \mu \mathrm{m}$ pore size). To the lower chamber, TSP-1 $(5 \mu \mathrm{g} / \mathrm{ml})$ and VEGF (50 ng/ml) were added alone or together. Cell migration in each chamber was determined. The data are presented in relative fluorescent units (RFU). Each bar diagram represents mean \pm S.E.M.; $n=4 .{ }^{*} P<0 \cdot 01$ compared with the rest of the groups.

negative balance between pro-angiogenic factors and antiangiogenic factors. The suppression of the level of TSP-1 in the pituitary during estradiol-induced tumor progression, as shown by increased PRL production, supports an antiangiogenic function for TSP-1 in this tissue.

TSP-1 has been shown to inhibit adhesion, proliferation, and tube formation of several types of endothelial cells in culture (Amstrong \& Bornstein 2003). Overexpression of TSP-1 in several tumor lines results in a reduced rate of subcutaneous tumor growth as a consequence of reduced angiogenesis (de Fraipont et al. 2001). In the pituitary, we found significant amounts of TSP-1 immunoreactivity in the endothelial cells. TSP-1 also significantly decreased cell proliferation and migration of pituitary-derived endothelial cells. In many tissues and tumors, TSP-1 has been shown to inhibit angiogenesis by inhibiting endothelial cell migration and proliferation and by inducing apoptosis (reviewed in Ren et al. 2006). Down-regulation of TSP-1 has also been suggested to alter tumor growth by modulating angiogenesis in a variety of tumor types (Lawler \& Detmar 2004). 
The TSP-1 level in the pituitary endothelial cells was decreased during lactotropic cell tumor development after estradiol treatment, providing support to the anti-angiogenic function of the locally produced glycoprotein molecule. In this context, it is interesting to note that the levels of CD31 in the pituitary cells did not change after estradiol treatment. This result suggests that the action of estradiol on TSP-1 is specific and is not due to a general inhibitory action on endothelial cells. Since we measured the CD31 protein level/ per cell and not the total amount of CD31 protein/tissue, the level of CD31 protein in the pituitary reflected the changes in the expression of this protein in endothelial cells rather than the changes in the number of endothelial cells. Hence, the observed absence of changes in the CD31 protein level after estradiol treatment are not in contrast to the well-known effect of estradiol on endothelial cell number (Turner et al. 2003).

Using a human endothelial cell line in culture, previously it has been shown that estradiol transiently (within $2 \mathrm{~h}$ ) suppresses expression and secretion of TSP-1 from these cells (Sengupta et al. 2004). We found that estradiol suppressive action on the cellular levels of TSP-1 in rat pituitary primary endothelial cells lasts for a long period of time; a minimum period of $18 \mathrm{~h}$ in vitro and several weeks in vivo. In spite of the differences between the duration of the action of estradiol on TSP-1 levels between the human endothelial cell line and rat primary pituitary endothelial cells, the steroid inhibited TSP-1 production in both of these cell types.

In conclusion, the data presented here demonstrated that estrogen is capable of suppressing TSP-1 levels in endothelial cells of the pituitary and that the increased level of TSP-1 in culture environment impedes the angiogenic factor action on the proliferation and migration of the pituitary endothelial cells. Together, these findings argue in favor of an inhibitory role of TSP-1 in estrogen-induced regulation of angiogenesis in the pituitary.

\section{Acknowledgements}

This work was supported by National Institutes of Health grants AA 11591 and CA 77550. The authors would like to thank NIDDK for providing PRL antibody. The authors declare that there is no conflict of interest that would prejudice the impartiality of this scientific work.

\section{References}

Adams JC \& Lawler J 2004 The thrombospondins. International Journal of Biochemistry and Cell Biology 36 961-968.

Amstrong LC \& Bornstein P 2003 Trrombospondins 1 and 2 function as inhibitor of angiogenesis. Matrix Biology 22 63-71.
Banerjee SK, Sarkar DK, Weston AP, De A \& Campbell DR 1997 Over expression of vascular endothelial growth factor and its receptor during the development of estrogen-induced rat pituitary tumors may mediate estrogen-initiated tumor angiogenesis. Carcinogenesis 18 1155-1161.

Chaturvedi K \& Sarkar DK 2004 Involvement of PKC dependent p44/42 MAP kinase signaling pathway for cross talk between estradiol and TGF- $\beta 3$ in increasing bFGF in folliculo-stellate cells. Endocrinology 145 706-715.

Chaturvedi K \& Sarkar DK 2006 Isolation and characterization of rat pituitary endothelial cells. Neuroendocrinology 83 387-395.

De la Torre NG, Turner HE \& Wass JA 2005 Angiogenesis in prolactinomas: regulation and relationship with tumour behaviour. Pituitary 8 17-23.

Elias KA \& Weiner RI 1987 Inhibition of estrogen-induced anterior pituitary enlargement and arteriogenesis by bromocriptine in Fischer 344 rats. Endocrinology 120 617-621.

Errio A, Bassetti M, Spada A \& Giannattasio G 1986 Microvasculature of human micro- and macroprolactinomas. A morphological study. Neuroendocrinology 43 159-165.

Folkman J 1995 Angiogenesis in cancer, vascular, rheumatoid and other disease. Nature Medicine 1 27-31.

Folkman J 1996 Tumor angiogenesis. In The Molecular Basis of Cancer, pp 206232. Eds J Mendelsohan, PM Howley, MA Israel \& LA Llotta. Philadelphia: WB Saunders Co.

de Fraipont F, Nicholson AC, Feige JJ \& Van Meir EG 2001 Thrombospondins and tumor angiogenesis. Trends in Molecular Medicine 7 401-407.

Gooren LJ, Assies J, Asscheman H, de Slegte R \& van Kessel H 1988 Estrogen-induced prolactinoma in a man. Journal of Clinical Endocrinology and Metabolism 66 444-446.

Gorczyca W \& Hardy J 1988 Microadenomas of the human pituitary and their vascularization. Neurosurgery $221-6$.

Hanahan H \& Folkman J 1996 Patterns and emerging mechanisms of the angiogenic switch during tumorigenesis. Cell 86 353-364.

Hardy J, Beauregard H \& Robert F 1980 Prolactin-secreting pituitary adenomas: transsphenoidal microsurgical treatment. Clinical Neurosurgery 27 $38-47$.

Hentges S \& Sarkar DK 2001 Transforming growth factor-beta regulation of estradiol-induced prolactinomas. Frontiers in Neuroendocrinology 22 340-363.

Jugenburg M, Kovac K, Stefaneanu L \& Scheithauer BW 1995 Vasculature in nontumorous hypophyses, pituitary adenomas, and carcinomas: a quantitative morphologic study. Endocrine Pathology 6 115-124.

Kalluri R 2003 Basement membranes: structure assembly and role in tumor angiogenesis. Nature Reviews: Cancer 3 422-433.

Lawler J 2002 Thrombospondin-1 as an endogenous inhibitor of angiogenesis and tumor growth. Journal of Cellular and Molecular Medicine 6 1-12.

Lawler J \& Hynes RO 1986 The structure of human thrombospondin, an adhesive glycoprotein with multiple calcium-binding sites and homologies with several different proteins. Journal of Cell Biology 103 1635-1648.

Lawler J \& Detmar M 2004 Tumor progression: the effects of thrombospondin-1 and -2. International Journal of Biochemistry and Cell Biology 36 $1038-1045$.

Monnet F, Elias KA, Fagin K, Neill A, Godsmith P \& Weiner RI 1984 Formation of a direct arterial blood supply to the anterior pituitary gland following complete or partial interruption of the hypophyseal portal vessels. Neuroendocrinology 39 251-255.

Nguyen M, Shing Y \& Folkman J 1994 Quantitation of angiogenesis and antiangiogenesis in the chick embryo chorioallantoic membrane. Microvascular Research 47 30-40.

Parums DV, Cordell JL, Micklem K, Heryet AR, Gatter KC \& Mason DY 1990 JC70: a new monoclonal antibody that detects vascular endothelium associated antigen on routinely processed tissue sections. Journal of Clinical Pathology 43 752-757.

Relf M, LeJeune S \& Scott PA 1997 Expression of the angiogenic factors vascular endothelial cell growth factor, acid and basic fibroblast growth factor, tumor growth factor $\beta 1$, platelet-derived endothelial cell growth factor, placenta growth factor, and pleiotropin in human primary breast cancer and its relation to angiogenesis. Cancer Research 57 963-1069.

Ren B, Yee KO, Lawler J \& Khosravi-Far R 2006 Regulation of tumor angiogenesis by thrombospondin-1. Biochimica et Biophysica Acta 1765 178-188. 
Sarkar DK 2006 Genesis of prolactinomas: studies using estrogen-treated animals. Frontiers of Hormone Research 35 32-49.

Sarkar DK, Gottschall PE \& Meites J 1982 Damage to hypothalamic dopaminergic neurons is associated with development of prolactinsecreting tumors. Science 218 684-686.

Sarkar DK, Pastorcic M, De A, Engel M, Moses H \& Ghasemzadeh MB 1998 Role of TGF- $\beta$ type I and TGF- $\beta$ type II receptors in the TGF- $B 1$ regulated gene expression in pituitary prolactin-secreting lactotropes. Endocrinology 138 3620-3628.

Schecter J, Goldsmith P, Wilson C \& Weiner R 1988 Morphological evidence for the presence of arteries in human prolactinomas. Journal of Clinical Endocrinology and Metabolism 67 713-719.

Sengupta K, Banerjee S, Saxena NK \& Banerjee SK 2004 Thombospondin-1 disrupts estrogen-induced endothelial cell proliferation and migration and its expression is suppressed by estradiol. Molecular Cancer Research 2 $150-158$.
Sid B, Sartelet H, Bellon G, Btaouri HEl, Rath G, Delorme N, Haye B \& Martiny L 2004 Thrombospondine 1: a multifunctional protein implicated in the regulation of tumor growth. Critical Reviews in Oncology/Hematology 49 245-258.

Turner H, Harris AL, Melmed S \& Wass JAH 2003 Angiogenesis in endocrine tumors. Endocrine Reviews 24 600-632.

Vidal S, Kovacs K, Horvath E, Scheithauer BW, Kuroki T \& Lloyd RV 2001 Microvessel density in pituitary adenomas and carcinomas. Virchows Archiv 438 595-602.

Received in final form 8 August 2006

Accepted 31 October 2006

Made available online as an Accepted Preprint 15 November 2006 